\title{
Dose-response effects of an antimicrobial peptide, a cecropin hybrid, on growth performance, nutrient utilisation, bacterial counts in the digesta and intestinal morphology in broilers
}

\author{
Liu-Fa Wen ${ }^{1,2 *}$ and Jian-Guo $\mathrm{He}^{1}$ \\ ${ }^{1}$ School of Life Science, Sun Yat-Sen University, Guangzhou 510275, People's Republic of China \\ ${ }^{2}$ College of Animal Science, South China Agricultural University, Guangzhou 510642, People's Republic of China \\ (Submitted 17 February 2011 - Final revision received 30 November 2011 - Accepted 30 November 2011 - First published online 17 January 2012)
}

\section{Abstract}

The aim of the present study was to evaluate the feasibility of an antimicrobial peptide, cecropin A(1-11)-D(12-37)-Asn (CADN), as an alternative to antibiotic growth promoter (AGP) in poultry diets. A total of 1500 14-d-old indigenous male chickens (222 (SD 13) g) were randomly allocated to five groups with five replicate cages of sixty birds each, and fed ad libitum five grower diets and subsequently five finisher diets for $14 \mathrm{~d}$ each. The diets were made up by supplementing their basal diets with a CADN liquid sample (CADNL) at 0,2 , 4 , 6 and $8 \mathrm{ml} / \mathrm{kg}$, respectively. During the feeding period, a metabolic experiment was carried out to determine the apparent digestibility of diethyl ether extract, nitrogen retention and apparent metabolisable energy of the diet sample fed to each cage of chicks. At the end of the feeding experiment, one chick from each cage was killed for bacteriological, light microscopic and scanning electron microscopic examination of the intestinal villi. CADN had a negative linear, positive quadratic and negative linear effect on feed intake (F), weight gain (G) and feed:gain ratio (F:G), respectively, for the growers; it had a quadratic effect on F, G or F:G for the finishers; it increased nutrient utilisation for both growers and finishers; it decreased aerobic bacterial counts in both jejunal and caecal digesta in a dose-dependent manner; it enhanced intestinal villus heights in a dose-dependent manner and made the duodenum villi of the CADNL8 group at $42 \mathrm{~d}$ appear as a netted leaf-like structure. CADN is therefore a possible alternative to AGP in broiler feeds.

Key words: Antimicrobial peptides: Cecropin: Broilers: Growth performance: Villi

Antimicrobial peptides (AMP) are evolutionarily conserved components of the innate immune response, found among all classes of life ranging from prokaryotes to humans, and a promising family of natural alternatives to antibiotic growth promoters (AGP) with vast diversity in terms of sources, structures, functionalities, antimicrobial spectra and modes of action $^{(1-3)}$. Currently, 1711 AMP have been identified from a wide range of organisms (http://aps.unmc.edu/AP/main.php; accessed February 2011). Recent research demonstrated that AMP could improve the growth performance of piglets ${ }^{(4,5)}$, growing-finishing pigs ${ }^{(6)}$, chickens $^{(7)}$ and fishes ${ }^{(8)}$, and the integrity of intestinal surfaces and intestinal mucosal response of chickens ${ }^{(7,9,10)}$. It seems that AMP are suited to be alternatives to AGP, but the use of AMP from natural sources is not at present cost-effective. Those AMP consisting of a single polypeptide chain of common amino acids are well suited for large-scale production by recombinant expression methods using micro-organisms that are resistant to the produced AMP.

Cecropins A (K W K L F K K I E K V G Q N I R D G I I K A G PAVAVVG Q A T Q I A K) and D (W N P F K E L E K V G Q R V R D A V I S A G P A V A T VA Q A T A L A K) belong to the cecropin family of AMP. They were originally isolated from the insect Hyalophora cecropia, and exerted strong antibiotic activity against Gram-positive and Gram-negative bacteria at micromolar concentrations ${ }^{(11)}$. The chimeric peptide, cecropin A(1-11)-D(12-37) (K W K L F K K I E K V - G Q R V R D A V I S A G P A V A T VA Q A T A L A K), which has the first eleven residues from the $\mathrm{N}$ terminus of cecropin $\mathrm{A}$ and the last twenty-six residues from the $\mathrm{C}$ terminus of cecropin $\mathrm{D}$, had greater antimicrobial activities than the parent peptides ${ }^{(12,13)}$. Because cecropins with an amidated $\mathrm{C}$ terminus have

Abbreviations: ADEE, apparent digestibility of diethyl ether extract; ADG, average daily weight gain; AGP, antibiotic growth promoter; AME, apparent metabolisable energy; AMP, antimicrobial peptides; CADN, cecropin A(1-11)-D(12-37)-Asn; CADNL, cecropin A(1-11)-D(12-37)-Asn liquid sample; F, feed intake; F:G, feed:gain ratio; G, weight gain; GIT, gastrointestinal tract; MEMP, dietary apparent metabolisable energy:apparent metabolisable protein ratio; NR, nitrogen retention; PB, phosphate buffer; YPCT, yeast fermentation broth containing yeast extract, peptone, maize steep powder and trisodium phosphate. 
broad-spectrum properties ${ }^{(14)}$, cecropin $\mathrm{A}(1-11)-\mathrm{D}(12-37)$ was amidated by adding Asn to its C-terminus to produce a more potent AMP, cecropin A(1-11)-D(12-37)-Asn (K W K L F K K I E K V - G Q R V R D A V I S A G P A V A T V A Q A T A $\mathrm{L} A \mathrm{~K}-\mathrm{N})(\mathrm{CADN})$, through the application of the recombinant DNA expressed in Pichia pastoris, using plasmid $\operatorname{pPlCZ} \alpha-A$ (Invitrogen) as the expression vector ${ }^{(15)}$.

The purpose of the present study was to verify the in vivo antimicrobial activity of CADN and its effects on the growth performance, nutrient utilisation and intestine villus morphology of broilers, to evaluate the feasibility of CADN serving as a possible alternative to AGP in poultry diets.

\section{Materials and methods \\ Preparation of cecropin A(1-11)-D(12-37)-Asn liquid sample}

In brief, one colony of genetically engineered $P$. pastoris strain GS-CAD (Chinese patent no.: CN01107584.8) was selected from yeast-growing plate ( $1 \%$ yeast extract $+2 \%$ peptone $+2 \%$ dextrose $+2 \%$ agar, $\mathrm{pH}$ 6.3-6.5) containing $500 \mu \mathrm{g}$ zeocin $/ \mathrm{ml}$ (stored at $4^{\circ} \mathrm{C}$; Invitrogen), grown in $100 \mathrm{ml}$ of sterile yeast-growing broth ( $1 \%$ yeast extract $+2 \%$ peptone $+2 \%$ dextrose, $\mathrm{pH} 6 \cdot 3-6.5)$ in $500 \mathrm{ml}$ flasks and shaken $\left(30^{\circ} \mathrm{C}, 200 \mathrm{rpm}\right)$ for $24 \mathrm{~h}$ to obtain $100 \mathrm{ml}$ of inoculum. The inoculum was added to 35 litres of sterile yeast fermentation broth (YPCT, 1\% yeast extract $+2 \%$ peptone $+2 \%$ maize steep powder $+0.2 \%$ trisodium phosphate, $\mathrm{pH} 6 \cdot 3-$ 6.5) in a bioreactor (BIOF-50L/S; Shanghai Gaoji Biology Engineering Company Limited) with 50 litres of working volume. The temperature was maintained at $30^{\circ} \mathrm{C}$, vessel pressure to be $0 \cdot 08-0 \cdot 1 \mathrm{MPa}$ and impeller speed set to $300 \mathrm{rpm}$. Medical grade oxygen was fed to the bioreactor to maintain dissolved oxygen concentration at $6-7 \mathrm{mg} / \mathrm{l}$. The $\mathrm{pH}$ was adjusted to the desired point during fermentation by automatic feeding of $30 \%(\mathrm{w} / \mathrm{w})$ ammonium hydroxide. About 0.35 litres of $95 \%$ methanol were fed in the logarithmic growth phase to induce the expression of the CADN gene for $72 \mathrm{~h}$. When the fermentation was completed, saturated steam was passed through the fermentation vessel for $10 \mathrm{~min}$ to kill the yeast cells, and YPCT was centrifuged at $6000 \mathrm{~g}$ for $10 \mathrm{~min}$ and the supernatant fractions were harvested for the experimental use. Determination of in vitro antibacterial activity of the CADN liquid sample (CADNL) was performed as described previously ${ }^{(16)}$. One unit of antibacterial activity was defined as the amount of AMP giving 50\% reduction of the absorbance at $570 \mathrm{~nm}$ compared with the control. The number of units was estimated by the following formula: $U=\sqrt{\left(A_{0}-A\right) / A}$, where $A$ is the absorbance in the sample and $A_{0}$ is the absorbance in the control. The in vitro antibacterial activity against Escherichia coli $\mathrm{K}_{12} \mathrm{D}_{31}$ of the CADNL used in the experiment was about $6000 \mathrm{U} / \mathrm{ml}$.

\section{Preparation of yeast fermentation broth free of cecropin A(1-11)-D(12-37)-Asn}

In brief, one colony of wild-type (untransformed) P. pastoris strain GS 1151 was grown in YPCT, and YPCT was harvested according to the above procedures.

\section{Diets}

For the experiment, two basal diets meeting or exceeding the National Research Council ${ }^{(17)}$ nutrient requirements for grower and finisher broilers were made, respectively. The chemical composition of the two basal diets is shown in Table 1. Broilers were fed with five experimental grower or finisher diets which were prepared by supplementing their basal diet with CADNL or YPCT free of CADN, and then produced in pellet form. The five grower diets were as follows: (1) basal diet + YPCT at $8 \mathrm{ml} / \mathrm{kg}$, (2) basal diet + YPCT at

Table 1. Ingredients and chemical composition of the experimental basal diets*

\begin{tabular}{lrrlrr}
\hline Ingredients $(\mathrm{g} / \mathrm{kg})$ & Grower & Finisher & Chemical composition (\%) & Grower & Finisher \\
\hline Maize & 654.0 & 663.4 & CP & 19.0 & 17.5 \\
Soyabean meal & 226.0 & 206.0 & AME $(\mathrm{MJ} / \mathrm{kg})$ & 12.07 & 12.47 \\
Maize gluten meal & 35.0 & 40.0 & Ca & 0.83 & 0.75 \\
Fishmeal & 25.0 & 10.0 & Total P & 0.63 & 0.60 \\
Vegetable oil & 15.0 & 30.0 & Available P & 0.42 & 0.40 \\
Limestone & 10.0 & 9.0 & NaCl & 0.33 & 0.30 \\
Dicalcium phosphate & 14.0 & 15.0 & Lys & 1.04 & 0.95 \\
Met & 1.2 & 1.6 & Met & 0.49 & 0.53 \\
Lys & 1.5 & 2.3 & Met + Cys & 0.66 & 0.60 \\
Salt & 2.5 & 2.5 & Thr & 0.76 & 0.69 \\
Premix & 3.0 & 3.0 & Trp & 0.22 & 0.20 \\
Bentonite & 12.8 & 17.2 & & & \\
Total (g) & 1000 & 1000 & & & \\
\hline
\end{tabular}

$\mathrm{CP}$, crude protein; AME, apparent metabolisable energy.

${ }^{*}$ Estimated from the data of the Chinese Animal Nutrition Association ${ }^{(39)}$.

†Premix contains the following: vitamin premix $1000 \mathrm{mg}$; mineral premix $1000 \mathrm{mg}$; antioxidant butylhydroxyanisol $250 \mathrm{mg}$; maduramycin $5 \mathrm{mg}$; mould inhibitors $500 \mathrm{mg}$; wheat bran $245 \mathrm{mg}$. The mineral premix provided (per $\mathrm{kg}$ of diet): $80 \mathrm{mg} \mathrm{Fe} ; 8 \mathrm{mg} \mathrm{Cu} ; 40 \mathrm{mg} \mathrm{Zn;} 60 \mathrm{mg} \mathrm{Mn} ; 0.35 \mathrm{mg} \mathrm{I} ; 0.07 \mathrm{mg} \mathrm{Co} ; 0.15 \mathrm{mg}$ Se. The vitamin premix provided (per $\mathrm{kg}$ of diet): $4968 \mu \mathrm{g}$ vitamin A palmitate; $45 \mu \mathrm{g}$ cholecalciferol; $30 \mathrm{mg}$ DL- $\alpha$-tocopheryl acetate; $1 \mathrm{mg}$ menadione; $1 \mathrm{mg}$ thiamin; $10 \mathrm{mg}$ riboflavin; $4 \mathrm{mg}$ pyridoxine; $0.02 \mathrm{mg}$ cyanocobalamin; $30 \mathrm{mg}$ niacin; $12 \mathrm{mg}$ pantothenic acid; $0.5 \mathrm{mg}$ folic acid; $0.2 \mathrm{mg}$ biotin. Vitamin supplement was over-adjusted for each vitamin so that after the feed pelleting process, vitamins would still be available. 
$6 \mathrm{ml} / \mathrm{kg}+\mathrm{CADNL}$ at $2 \mathrm{ml} / \mathrm{kg}$, (3) basal diet + YPCT at $4 \mathrm{ml} /$ $\mathrm{kg}+\mathrm{CADNL}$ at $4 \mathrm{ml} / \mathrm{kg}$, (4) basal diet + YPCT at $2 \mathrm{ml} / \mathrm{kg}+$ CADNL at $6 \mathrm{ml} / \mathrm{kg}$, (5) basal diet + CADNL at $8 \mathrm{ml} / \mathrm{kg}$. Similarly, the five finisher diets were prepared using the finisher basal diet and also produced in pellet form.

\section{Birds and management}

The feeding experiment was carried out in the Poultry Research and Teaching Farm of South China Agricultural University, with all procedures approved by the Animal Care and Use Committee of South China Agricultural University, according to the Regulations for the Administration of Affairs Concerning Experimental Animals (approved by the State Council of the People's Republic of China on 31 October 1988 and promulgated by Decree no. 2 of the State Science and Technology Commission of the People's Republic of China on 14 November 1988). A total of 1500 fourteen-dayold Lingnan Yellow male chickens, 222 (SD 13) g of body weight, from the Guangdong Academy of Agricultural Sciences (Guangzhou, Guangdong Province, China), in a completely randomised design, were randomly allocated to five groups with five replicate cages of sixty birds each, fed ad libitum the five grower (15-28d of age) diets, respectively, and subsequently fed the five finisher (29-42d of age) diets, respectively. During the feeding period, the chicks were provided water ad libitum and raised in illumination $(24 \mathrm{~h} / \mathrm{d})$ by overhead fluorescent lighting, the daily feed intake (F) per cage of birds and daily feed intake per bird were recorded, and mortality in each cage was recorded if there were birds dead.

At the end of each feeding period, average daily feed intake (ADF, g/bird per d), average daily weight gain (ADG, g/bird per $\mathrm{d}$ ), ADF:ADG ratio (F:G, g/g) and average mortality (\%) for each cage were calculated, respectively.

\section{Metabolic experiment}

During the feeding experiments, about $100 \mathrm{~g}$ excreta from each cage of chicks was collected daily by laying a stainlesssteel plate $(100 \mathrm{~cm} \times 150 \mathrm{~cm})$ directly beneath each cage from 08.00 to 10.00 hours, and immediately stored in a ziplock plastic bag at $-20^{\circ} \mathrm{C}$. At the end of each feeding period, the daily excreta collections were pooled for each cage of birds, oven-dried at $65^{\circ} \mathrm{C}$ to constant weight, weighed and ground to a consistent particle size through a 40 mesh screen before analysis. Samples of the diets and excreta were assayed for gross energy with a bomb calorimeter (HWR-15C; Shanli Detecting Instrument Factory under the Shanghai Testing Technology Institute), nitrogen contents with a Kjeltec auto-analyzer (Kjeltec 2300; Foss Tecator), diethyl ether extract contents with a Soxtec Avanti fat extraction system (Soxtec 2050; Foss Tecator), and acid-insoluble ash contents using the procedure described earlier ${ }^{(18)}$ with a spectrophotometer (UV-2550/2450; Shimadzu).

The apparent metabolisable energy (AME), nitrogen retention (NR), apparent digestibility of diethyl ether extract (ADEE) for the diet consumed by each cage of chicks were calculated as follows:

$$
\begin{aligned}
\operatorname{AME}(\mathrm{MJ} / \mathrm{kg}) & =\left(\mathrm{GE}_{\mathrm{d}}-\mathrm{GE}_{\mathrm{e}} \times \mathrm{AIA}_{\mathrm{d}} / \mathrm{AIA}_{\mathrm{e}}\right) / 1000 ; \\
\mathrm{NR}(\%) & =100 \times\left(\mathrm{N}_{\mathrm{d}}-\mathrm{N}_{\mathrm{e}} \times \mathrm{AIA}_{\mathrm{d}} / \mathrm{AIA}_{\mathrm{e}}\right) / \mathrm{N}_{\mathrm{d}} ; \\
\operatorname{ADEE}(\%) & =100 \times\left(\mathrm{EE}_{\mathrm{d}}-\mathrm{EE}_{\mathrm{e}} \times \mathrm{AIA}_{\mathrm{d}} / \mathrm{AIA}_{\mathrm{e}}\right) / \mathrm{EEd},
\end{aligned}
$$

where $G_{d}$, is the gross energy of the $\operatorname{diet}(\mathrm{J} / \mathrm{g}) ; \mathrm{GE}_{\mathrm{e}}$, is the gross energy of the excreta $(\mathrm{J} / \mathrm{g}) ; \mathrm{AIA}_{\mathrm{d}}$, is acid-insoluble ash contents $(\mathrm{g} / \mathrm{kg})$ of the diet; $\mathrm{AIA}_{\mathrm{e}}$, is acid-insoluble ash contents $(\mathrm{g} / \mathrm{kg})$ of the excreta; $\mathrm{N}_{\mathrm{d}}$, is the nitrogen content of the diet $(\%) ; \mathrm{N}_{\mathrm{e}}$, is the nitrogen content of the excreta (\%); $\mathrm{EE}_{\mathrm{d}}$, is the diethyl ether extract content of the diet $(\%) ; \mathrm{EE}_{\mathrm{e}}$, is the diethyl ether extract content of the excreta (\%).

$\operatorname{AME}$ intake $(\mathrm{kJ} /$ bird per $\mathrm{d})=\mathrm{ADF} \times \mathrm{AME}$.

Dietary AME : apparent metabolisable protein ratio (MEMP) $(\mathrm{MJ} / \mathrm{kg})=10000 \mathrm{AME} /(\mathrm{NR} \times$ crude protein $)$.

\section{Bacteriological examinations}

At the end of the feeding experiment, one chick from each replicate cage, with its body weight close to the mean, was chosen and killed by intravenous injection of sodium pentobarbital at $100 \mathrm{mg} / \mathrm{kg}$, and then the jejunal and caecal digesta were collected for the measurement of aerobic bacteria count according to the procedures of the Health Protection Agency $^{(19)}$. Approximately $1 \mathrm{~g}$ of each digesta sample was mixed with $9 \mathrm{ml}$ of sterile Peptone Saline Diluent (0.1\% peptone $+0.85 \% \mathrm{NaCl}, \mathrm{pH} 7 \cdot 0$ ), and homogenised for $3 \mathrm{~min}$. From the initial $10^{-1}$ dilution, ten-fold serial dilutions were subsequently made in sterile Peptone Saline Diluent. For each dilution, $0.1 \mathrm{ml}$ was inoculated onto the centre of a sterile and dried Plate Count Agar ( $0.25 \%$ yeast extract $+0.5 \%$ tryptone $+0 \cdot 1 \%$ glucose $+1 \cdot 2 \%$ agar, $\mathrm{pH} 7 \cdot 0)$ plate. A sterile spreader was used to spread the inoculum over the surface of each plate as soon as possible. The plates were left on the bench for approximately $15 \mathrm{~min}$ to allow absorption of the inoculum into the agar, then inverted and placed in an incubator at $30^{\circ} \mathrm{C}$ for $48 \mathrm{~h}$. The colonies on each plate were counted as soon as the plates were removed from the incubator. The quantity of bacteria was expressed as $\log _{10}$ (colony-forming units/g wet digesta) for each digesta sample.

\section{Scanning electron microscopic examination}

After the chick from the control or CADNL8 group was killed, the midpoint of the duodenum or jejunum was cut open longitudinally. From each intestine segment, three pieces of intestine inner surface tissue (about $1.0 \mathrm{~cm} \times 1.0 \mathrm{~cm}$ ) were removed, rinsed by gently flushing the debris from the tissue surface using cold $0 \cdot 1 \mathrm{~m}$-phosphate buffer ( $\mathrm{PB}$; $\mathrm{pH} 7 \cdot 2$ ) until visible feed particles and the mucus had been removed, and then immediately fixed in $4 \%$ glutaraldehyde (in PB) overnight. After being washed in PB for $5 \mathrm{~min}$, these specimens were post-fixed in $1 \%$ osmium tetroxide (in $\mathrm{PB}$ ) for $2 \mathrm{~h}$, washed in $\mathrm{PB}$ for $5 \mathrm{~min}$ again, and dehydrated, respectively, in graded ethanol solutions (50, 70, 80, 90, 100 and 
$100 \%$ ) and amyl acetate ester for 15 min. Afterwards, the specimens were vacuum-dried in a freeze-drying apparatus (CHRIST ALPHA 1-4) until all observable surface solvent had been removed, mounted on aluminium stubs, coated with gold palladium for $30 \mathrm{~min}$, and finally examined with a scanning electron microscope (Philips XL-30 ESEM) using the secondary electron mode at an accelerating voltage of $10.0 \mathrm{kV}$ and magnifications $200 \times$. The clearest villus images were selected for comparison of morphological changes in villi between the two treatment groups.

\section{Light microscopic examination}

After the chicks from each cage were killed, the duodenum from the gizzard to the pancreatic and bile ducts and the ileum from the Meckel's diverticulum to the ileum-caecal junction were collected, and flushed with saline (0.90\% $\mathrm{NaCl}, \mathrm{w} / \mathrm{v})$. A $2 \mathrm{~cm}$ length of each intestinal midpoint was fixed in $10 \%$ buffered formalin ( $\mathrm{pH} \mathrm{7.0)}$ ) and embedded with paraffin wax. From each intestinal segment, ten transverse sections were cut at a thickness of $5 \mu \mathrm{m}$ and fixed on each slide. After the ten transverse sections were stained with haematoxylin-eosin (Guangzhou Xiuwei Trading Company Limited), two villi per section were randomly selected to determine villus height (from the tip to the base, excluding the intestinal crypt) and crypt depth, using an image processing and analysis system (version 1; Leica Imaging Systems Limited).

From the ten stained sections in each intestinal segment per bird, the five most clearly stained sections were selected for the calculation of villus morphometric parameters; therefore, the averages of ten villus height, crypt depth and villus height: crypt depth values were expressed as the mean values, respectively, for each bird. Thereafter, one most clearly stained duodenum section of the control or CADNL8 group was photographed using an Olympus Vanox-S Light Microscope (Olympus).

\section{Statistical analysis}

The SPSS statistical software package (version 17.0 for Windows; SPSS China) was used for all statistical analyses. Multiple comparisons among means were determined by one-way ANOVA followed by Duncan's test (when equal variances were assumed) or Tamhane's $T_{2}$ test (when equal variances were not assumed). $P$ values $<0.05$ were considered significant. The correlate-bivariate and regression-curve estimation models were used to examine the linear and quadratic correlation between two sets of parameters. When a correlation coefficient $(r)$ was up to $0 \cdot 70$, the correlation was considered high; and when the coefficient of determination $\left(R^{2}\right)$ was up to $0 \cdot 8$, the goodness of fit of the observed data to the regression equation was considered acceptable.

\section{Results}

The growth performance and nutrient utilisation of growers are shown in Table 2. There were no differences in initial body weight $(P=0 \cdot 598)$, mortality $(P=0 \cdot 294)$, AME intake

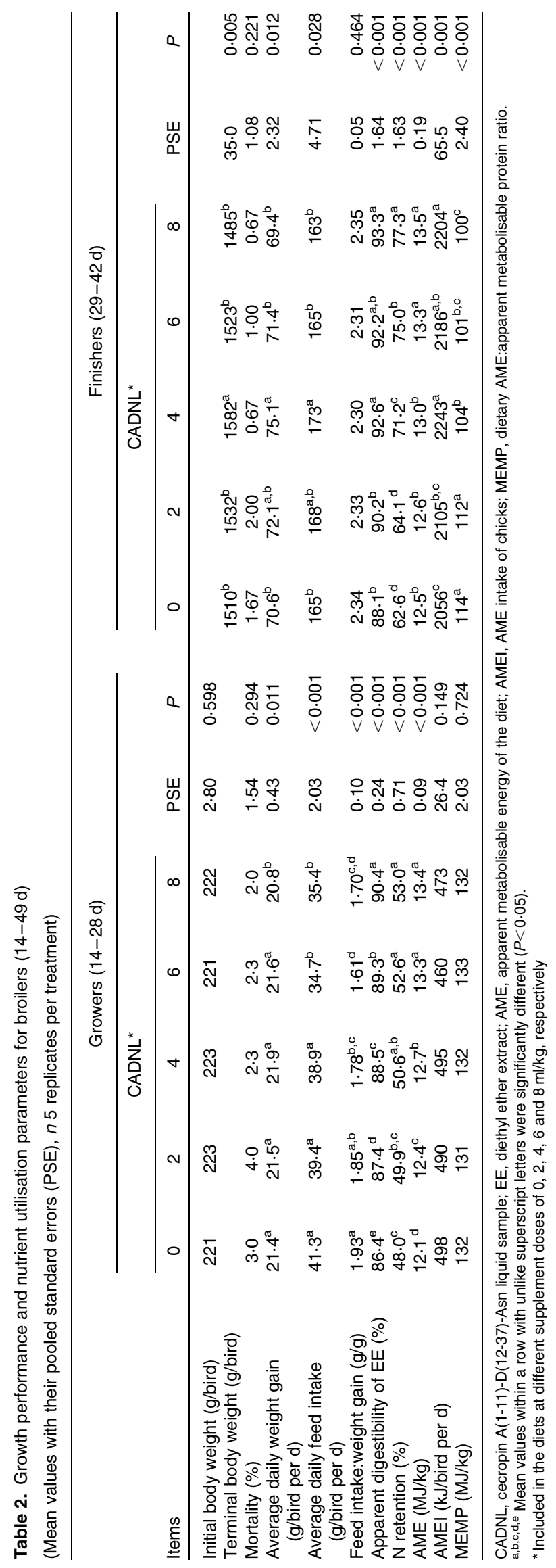


Table 3. Effect of cecropin $A(1-11)-D(12-37)-A s n$ (CADN) on the jejunal and caecal aerobic bacterial counts ( $\log _{10}$ colony-forming units/g wet digesta) of broilers at $42 \mathrm{~d}$ of age (Mean values with their pooled standard errors (PSE), $n 5$ replicate chicks per treatment)

\begin{tabular}{lccccccc}
\hline & \multicolumn{7}{c}{ CADNL* $^{*}$} \\
\cline { 2 - 6 } Items & 0 & 2 & 4 & 6 & 8 & PSE & $P$ \\
\hline Jejunal digesta & $6.97^{\mathrm{a}}$ & $6.81^{\mathrm{a}}$ & $6 \cdot 70^{\mathrm{a}}$ & $5 \cdot 20^{\mathrm{b}}$ & $4.73^{\mathrm{c}}$ & 0.222 & $<0.001$ \\
Caecal digesta & $9.00^{\mathrm{a}}$ & $8.54^{\mathrm{b}}$ & $7.48^{\mathrm{c}}$ & $7.22^{\mathrm{d}}$ & $6.90^{\mathrm{e}}$ & 0.121 & $<0.001$ \\
\hline
\end{tabular}

CADNL, CADN liquid sample.

$\mathrm{a}, \mathrm{b}, \mathrm{c}, \mathrm{d}, \mathrm{e}$ Mean values within a row with unlike superscript letters were significantly different $(P<0.05)$. *Included in the diets at different supplement doses of $0,2,4,6$ and $8 \mathrm{ml} / \mathrm{kg}$, respectively.

$(P=0 \cdot 149)$ or MEMP $(P=0.724)$ among the groups, but there were significant differences in ADG $(P=0 \cdot 011)$, ADF $(P<0.001)$, F:G $(P<0.001)$, ADEE $(P<0.001)$, NR $(P<0.001)$ or AME $(P<0 \cdot 001)$. CADNL had a quadratic effect on ADG $\left(\mathrm{ADG}=-0.045 \mathrm{CADNL}^{2}+0.302 \mathrm{CADNL}+21.303 ; r \quad 0.933\right.$, $R^{2} 0 \cdot 870$; with the optimum CADNL dose being $3 \cdot 4 \mathrm{ml} / \mathrm{kg}$ ), negative linear effects on ADF $(r-0.933)$ and $\mathrm{F}: \mathrm{G}$ $(r-0.885)$, and positive linear effects on ADEE ( $r$ 0.999), NR ( $r$ 0.980) and AME ( $r$ 0.985). AME had a positive linear correlation with ADEE ( $r$ 0.980) or NR ( $r$ 0.994), whereas ADF had a negative linear correlation with dietary AME $(r-0.980)$ but no correlations with MEMP.

The growth performance and nutrient utilisation of finishers are also shown in Table 2. There were no significant differences in mortality $(P=0 \cdot 221)$ and F:G $(P=0 \cdot 464)$, but significant differences in terminal body weight $(P=0.005)$, ADG $(P=0.012)$, ADF $(P=0.028)$, dietary ADEE $(P<0.001)$, NR $(P<0.001)$, AME $(P<0.001)$, AME intake $(P=0.001)$ and MEMP $(P<0 \cdot 001)$. CADNL had quadratic effects on terminal body weight ( $r$ 0.894), ADG (ADG $=-0.245$ $\mathrm{CADNL}^{2}+1.802 \mathrm{CADNL}+70.383 ; r 0.886, R^{2} 0.785 ;$ with the optimum CADNL dose being $3.7 \mathrm{ml} / \mathrm{kg}$ ), ADF $(r 0.838)$ and F:G ( $r$ 0.902), and had positive linear effects on dietary ADEE ( $r$ 0.974), NR ( $r$ 0.979) and AME ( $r$ 0.987). AME had a positive linear correlation with ADEE $(r$ 0.903) or NR ( $r$ 0.997), whereas ADF had no correlations with AME but a quadratic correlation with MEMP $(r-0.967)$.

The effects of CADN on the jejunal and caecal aerobic bacterial counts of broilers at $42 \mathrm{~d}$ of age are shown in Table 3. There were significant differences $(P>0.05)$ in aerobic bacterial counts in the digesta in the jejunum or caecum among the groups, and CADNL had a negative linear correlation with aerobic bacterial counts in the jejunal $(r-0.928$, $P=0.023)$ or caecal digesta $(r-0.971, P=0.006)$.

Intestinal villus height, crypt depth and villus height:crypt depth ratio of each group are shown in Table 4 . There were significant differences $(P<0 \cdot 001)$ in villus height, crypt depth and villus height:crypt depth ratio of the duodenum or ileum among the groups. CADN had a positive linear effect on villus height $(r 0.958, P=0.010)$ or villus height:crypt depth ratio $(r 0.904, P=0.035)$, but a negative linear effect on crypt depth $(r-0.865, P=0.058)$ of the duodenum; similarly, CADN had a positive linear effect on villus height ( $r$ 0.884, $P=0.046)$ or villus height:crypt depth ratio ( $r$ 0.916, $P=0.029)$, but a negative linear effect on crypt depth $(r-0.875, P=0.052)$ of the ileum.

The comparisons of scanning electron microscope microphotographs of the duodenum and jejunum villi of broilers at $42 \mathrm{~d}$ of age between the control (CADNLO) and CADNL8 groups are shown in Fig. 1. The duodenum villi of the control group (Fig. 1(a)) were tongue-like, while those of CADNL8 (Fig. 1(b)) were leaf-like. As to the jejunum villi, the villi of the two groups were all tongue-like, but the villi of the control group appeared to have severe inflammation.

The difference in the histomorphology of villi in the duodenum between the control and CADNL8 groups is shown in Fig. 2. The duodenum villi of CADNL8 (Fig. 2(b)) were longer than the villi of the control group (Fig. 2(a)); furthermore, the villi of CADNL8 (Fig. 2(b)) anastomosed to form

Table 4. Villus height, crypt depth and villus height:crypt depth ratio of the duodenum and ileum of broilers at $42 \mathrm{~d}$ of age (Mean values with their pooled standard errors (PSE), $n 5$ replicate chicks per treatment)

\begin{tabular}{|c|c|c|c|c|c|c|c|}
\hline \multirow[b]{2}{*}{ Items } & \multicolumn{5}{|c|}{$\mathrm{CADNL}^{*}$} & \multirow[b]{2}{*}{ PSE } & \multirow[b]{2}{*}{$P$} \\
\hline & 0 & 2 & 4 & 6 & 8 & & \\
\hline \multicolumn{8}{|l|}{ Duodenum } \\
\hline Villus height $(\mu \mathrm{m})$ & $425^{d}$ & $466^{c}$ & $492^{b}$ & $512^{\mathrm{a}}$ & $516^{\mathrm{a}}$ & $12 \cdot 13$ & $<0.001$ \\
\hline Crypt depth $(\mu \mathrm{m})$ & $90^{\mathrm{a}}$ & $83^{\mathrm{b}}$ & $64^{c}$ & $66^{c}$ & $66^{c}$ & 3.87 & $<0.001$ \\
\hline Villus height:crypt depth ratio & $4 \cdot 7^{\mathrm{c}}$ & $5 \cdot 6^{\mathrm{b}}$ & $7 \cdot 7^{\mathrm{a}}$ & $7 \cdot 8^{\mathrm{a}}$ & $7 \cdot 8^{\mathrm{a}}$ & 0.42 & $<0.001$ \\
\hline \multicolumn{8}{|l|}{ Ileum } \\
\hline Villus height $(\mu \mathrm{m})$ & $345^{\mathrm{c}}$ & $438^{b}$ & $499^{a}$ & $508^{a}$ & $506^{\mathrm{a}}$ & 13.58 & $<0.001$ \\
\hline Crypt depth $(\mu \mathrm{m})$ & $143^{a}$ & $94^{\mathrm{b}}$ & $65^{c}$ & $64^{\mathrm{c}}$ & $62^{\mathrm{c}}$ & $8 \cdot 88$ & $<0.001$ \\
\hline Villus height:crypt depth ratio & $2 \cdot 5^{\mathrm{d}}$ & $4 \cdot 7^{\mathrm{c}}$ & $7 \cdot 7^{\mathrm{b}}$ & $7 \cdot 9^{a, b}$ & $8 \cdot 1^{a}$ & 0.28 & $<0.001$ \\
\hline
\end{tabular}

CADNL, CADNL, cecropin A(1-11)-D(12-37)-Asn liquid sample.

a,b,c,d Mean values within a row with unlike superscript letters were significantly different $(P<0.05)$

* Included in the diets at different supplement doses of $0,2,4,6$ and $8 \mathrm{ml} / \mathrm{kg}$, respectively. 

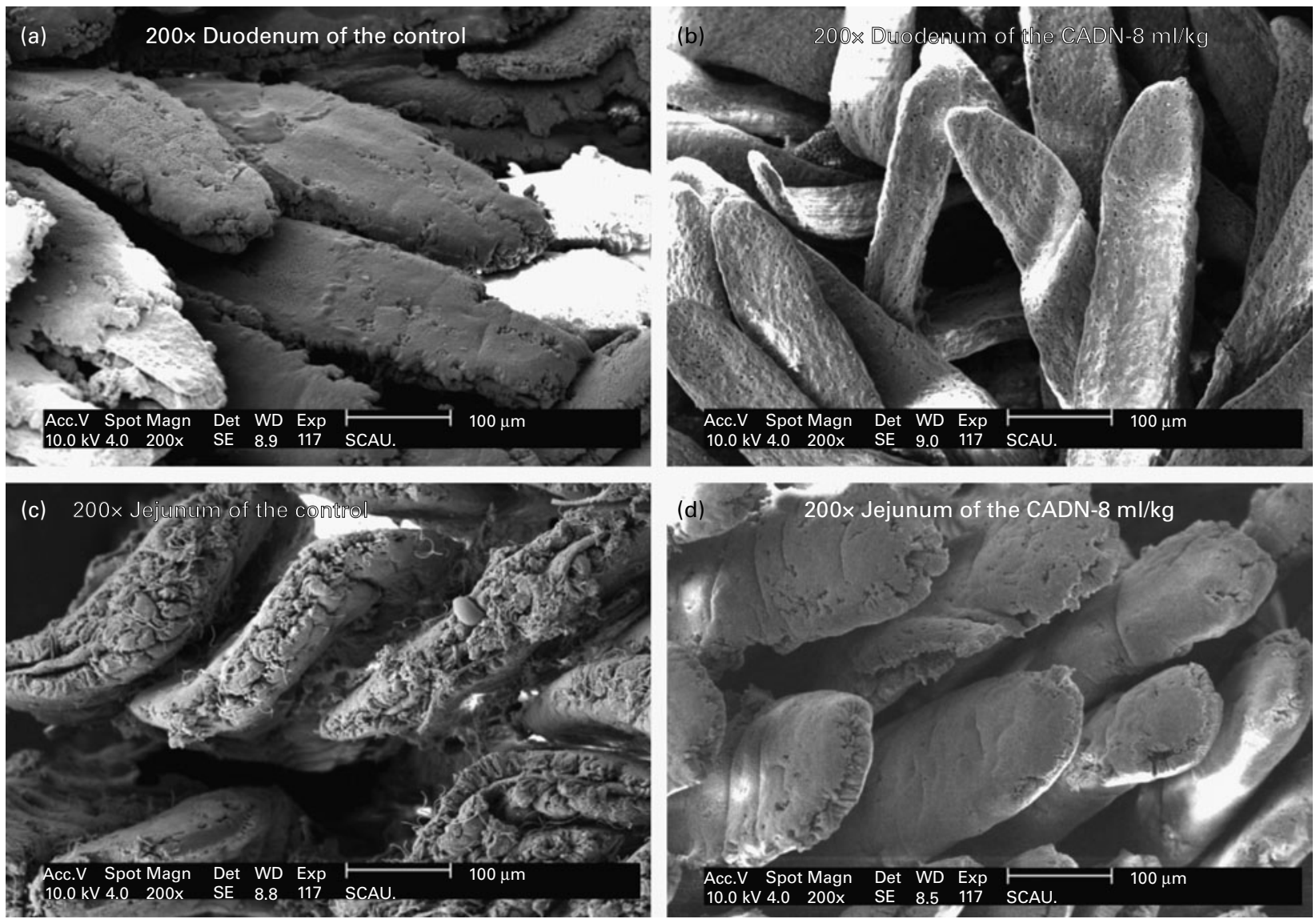

Fig. 1. Scanning electron microphotographs of the intestinal villi of Lingnan Yellow broilers at $42 \mathrm{~d}$ of age (at magnification $200 \times$ and $10.0 \mathrm{kV}$; scale bar $=100 \mu \mathrm{m}$ ). (a) Duodenum villi of the control group; (b) duodenum villi of the cecropin A(1-11)-D(12-37)-Asn liquid (CADNL8) group; (c) jejunum villi of the control group; (D) jejunum villi of the CADNL8 group.

a netted leaf-like structure, which was not found in the intestines of the control group.

\section{Discussion}

In the present study, CADN had a quadratic effect on ADG for both grower and finisher broilers, similar to the effect of salinomycin in pigs ${ }^{(20)}$ and lasalocid in beef cattle ${ }^{(21)}$. For the growers, MEMP was not significantly different among the groups, letting dietary energy be the limiting factor for feed intake and broilers decrease their feed intakes with dietary AME increasing to satisfy their requirements for a certain amount of energy for growth, in accordance with a previous result $^{(22)}$. For the finishers, MEMP was significantly different among the groups, letting broilers adjust their feed intakes in a quadratic response to varying MEMP to satisfy their requirements for optimum nutrient balance at a certain MEMP, in accordance with a previous result ${ }^{(23)}$.

Because CADN is a macromolecular peptide, and the level of the macromolecular peptide transferred to the portal
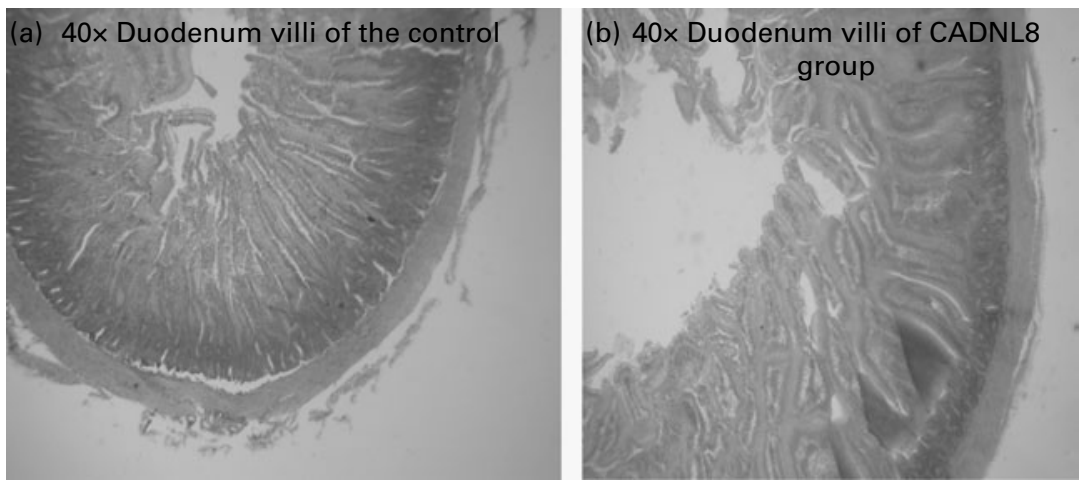

Fig. 2. Comparison of the villus histomorphology of broilers at $42 \mathrm{~d}$ of age. (a) Duodenum villi of the control group $(40 \times)$; (b) anastomosed duodenum villi of the cecropin $A(1-11)-D(12-37)-A s n$ liquid (CADNL8) group $(40 \times)$. 
blood of the animal was extremely low ${ }^{(24)}$, CADN should act only in the gastrointestinal tract (GIT). There was a widespread concern that AMP could be inactivated inside the GIT, because the GIT is rich in acids and proteinases. The present study indicated that CADN was effective in inhibiting bacterial growth in a dose-dependent manner in the GIT of the chickens, i.e. CADN could resist, to some extent, if not all, to the hydrolysis in the GIT of the chickens.

In the GIT, commensal bacteria may induce intestine inflammation by releasing metabolites, e.g. lipopolysaccharide from Gram-negative bacteria and lipoteichoic acid from Grampositive bacteria ${ }^{(25,26)}$. The metabolites may bind to a metabolite-binding protein and subsequently to CD14 to activate inflammatory responses through initiating Toll-like receptors 4 and 2 on macrophages ${ }^{(25,27)}$. In the present study, inflammation was found to be evident in the jejunum villi of the control group, indicating that $\mathrm{CADN}$ had an anti-inflammatory effect. The anti-inflammatory effect of CADN might result indirectly from its antibacterial effect, but whether it would have the following effects, similar to other AMP, needs to be studied: (1) neutralising bacterial metabolites to prevent the formation of metabolite-binding protein complex ${ }^{(28)}$, (2) directly and selectively inhibiting the expression of genes encoding the pro-inflammatory molecules in macrophages ${ }^{(27)}$, (3) increasing the expression of programmed cell death-1 to reduce $\mathrm{CD}^{+} \mathrm{T}$ cell-mediated enteric autoimmunity response and the subsequent inflammation ${ }^{(28,29)}$, (4) inducing caspase-independent apoptosis in the mucosal inflammatory cells $^{(30)}$.

The commensal microbiota hydrolyses bile acids and their salts required for proper fat digestion and absorption, and competes with the host for the uptake of nutrients and energy, thus decreasing utilisation efficiency of fat, protein and energy ${ }^{(31)}$, so in the present study, while decreasing aerobic bacterial counts in the digesta in a dose-dependent manner, CADN increased ADEE, NR and AME of the diets in a dose-dependent manner. This was similar to the results of many previous studies. An increase in dietary potato antimicrobial protein reduced populations of total aerobic bacteria in the caecum (day 42) of broilers, and linearly improved retention of dry matter (day 20 to 21) and crude protein (day 20 to 21 and day 41 to 42 ) in the diet ${ }^{(32)}$. Butyrate in the diet decreased $E$. coli numbers in the duodenum and improved the feed conversion of chickens ${ }^{(33)}$. CADN increasing the nutrient utilisation of the diets might also result from its anti-inflammatory effect, because the effect of AGP causes reduced accumulation of inflammatory cells in the mucosa, a thinner intestinal wall, thereby sparing energy for production $^{(25)}$.

In the present study, while decreasing the bacterial counts in the digesta and improving the efficiency of nutrient utilisation, CADN improved intestinal villus structures in a dosedependent manner. Because the commensal microbiota has adverse effects on intestinal villus structures by producing harmful metabolites ${ }^{(26,29,31,34)}$ and increased available nutrients promote the growth of the intestinal villi ${ }^{(35-38)}$, the mechanism for CADN improving villus structures might involve permitting villus growth by inhibiting bacterial growth and providing more available nutrients for villus growth. Whether CADN may directly promote villus growth should be studied with germ-free animals.

\section{Conclusions}

CADN inhibited gut bacterial growth, improved nutrient utilisation and intestine villus structures, and thus improved the growth of grower and finisher broilers with optimum CADNL doses being 3.4 and $3.7 \mathrm{ml} / \mathrm{kg}$, respectively. CADN is therefore a possible alternative to AGP in broiler feeds, but its safety for consumers and the environment needs to be studied.

\section{Acknowledgements}

The authors would like to thank Guo-qing Huang from Shenzhen Yipeng Biological Engineering Company, Limited (Shenzhen, Guangdong Province, China) for supporting the preparation of CADNL and YPCT free of CADN. We also thank the referees for their constructive and helpful comments, especially suggestions concerning the interpretation of the data and discussion on the manuscript. This study received no specific grant from any funding agencies in the public, commercial or not-for-profit sectors. J.-G. H. is the guarantor of the article. L.-F. W. is the principal investigator of the study. Both authors participated in the design, execution and data interpretation of the study and contributed to the various drafts of the manuscript. The authors approved the final draft of the manuscript. Neither of the authors has any conflicts of interests.

\section{References}

1. Hancock REW \& Lehrer R (1998) Cationic peptides: a new source of antibiotics. Trends Biotechnol 16, 82-88.

2. Parisien A, Allain B, Zhang J, et al. (2008) Novel alternatives to antibiotics: bacteriophages, bacterial cell wall hydrolases, and antimicrobial peptides. J Appl Microbiol 104, 1-13.

3. Keymanesh K, Soltani S \& Sardari S (2009) Application of antimicrobial peptides in agriculture and food industry. World J Microb Biot 25, 933-944.

4. Hong J, Kim I, Hwang I, et al. (2003) Evaluation of recombinant human lactoferricin culture as a substitute for antibiotic in pig starter diets. J Anim Sci Technol (Kor.) 45, 537-542.

5. Tang HR, Yin YL, Zhang YM, et al. (2009) Effects of dietary supplementation with an expressed fusion peptide bovine lactoferricin-lactoferrampin on performance, immune function and intestinal mucosal morphology in piglets weaned at age 21 d. Br J Nutr 101, 998-1005.

6. Cromwell GL, Davis GW, Morrow WE, et al. (1996) Efficacy of the antimicrobial compound U-82,127 as a growth promoter for growing-finishing pigs. J Anim Sci 74, 1284-1287.

7. Bao H, She R, Liu T, et al. (2009) Effects of pig antibacterial peptides on growth performance and intestine mucosal immune of broiler chickens. Poult Sci 88, 291-297.

8. Zhou XX, Wang YB \& Li WF (2008) Effect of feeding apidaecin on common carp (Cyprinus carpio) growth performances and immune function. Aquaculture 279, 108-112. 
9. Liu T, She R, Wang K, et al. (2008) Effects of rabbit sacculus rotundus antimicrobial peptides on the intestinal mucosal immunity in chickens. Poult Sci 87, 250-254.

10. Wang $\mathrm{D}, \mathrm{Ma} \mathrm{W}$, She $\mathrm{R}$, et al. (2009) Effects of swine gut antimicrobial peptides on the intestinal mucosal immunity in specific-pathogen-free chickens. Poult Sci 88, 967-974.

11. Hultmark D, Engström A, Bennich H, et al. (1982) Insect immunity: isolation and structure of cecropin D and four minor antibacterial components from cecropia pupae. Eur J Biochem 127, 207-217.

12. Christensen B, Fink J, Merrifield R, et al. (1988) Channelforming properties of cecropins and related model compounds incorporated into planar lipid membranes. Proc Natl Acad Sci U S A 85, 5072-5076.

13. Fink J, Memifield RB \& Baoman A (1989) The chemical synthesis of cecropin D and an analog with enhanced antibacterial activity. J Biol Chem 264, 6260-6267.

14. Li ZQ, Merrifield RB, Boman IA, et al. (1988) Effects on electrophoretic mobility and antibacterial spectrum of removal of two residues from synthetic sarcotoxin IA and addition of the same residues to cecropin B. FEBS Lett 231, 299-302.

15. Huang ZR, Huang YD, Wen LF, et al. (2005) Cecropin biotechnology and its application. Can Ye Kexue 31, 375-381 (in Chinese).

16. Hultmark D, Steiner H, Rasmuson $\mathrm{T}$, et al. (1980) Insect immunity. Purification and properties of three inducible bactericidal proteins from hemolymph of immunized pupae of Hyalophora cecropia. Eur J Biochem 106, 7-16.

17. NRC (1994) Nutrient Requirements of Poultry, 9th revised ed. Washington, DC: National Research Council.

18. Van Keulen J \& Young BA (1977) Evaluation of acid insoluble ash as a natural marker in ruminant digestibility studies. J Anim Sci 44, 282-287.

19. Health Protection Agency (2004) Aerobic plate count at $30^{\circ} \mathrm{C}$ : surface plate method. National Standard Method F10 Issue 1. http://www.hpa-standardmethods.org.uk/pdf_sops.asp (accessed February 2007).

20. Lindemann MD, Kornegay ET, Stahly TS, et al. (1985) The efficacy of salinomycin as a growth promotant for swine from 9 to $97 \mathrm{~kg}$. J Anim Sci $\mathbf{6 1}, 782-788$.

21. Bretschneider G, Elizalde JC \& Pérez FA (2008) The effect of feeding antibiotic growth promoters on the performance of beef cattle consuming forage-based diets: a review. Livest Sci 114, 135-149.

22. Veldkamp T, Kwakkel RP, Ferket PR, et al. (2005) Growth responses to dietary energy and lysine at high and low ambient temperature in male turkeys. Poult Sci 84, 273-282.

23. Mbajiorgu CA, Ng'ambi JW \& Norris D (2011) Effect of varying dietary energy to protein ratio level on growth and productivity of indigenous venda chickens. Asian J Anim Vet Adv 6, 344-352.

24. Wakabayashi H, Kuwata H, Yamauchi K, et al. (2004) No detectable transfer of dietary lactoferrin or its functional fragments to portal blood in healthy adult rats. Biosci Biotechnol Biochem 68, 853-860.

25. Niewold TA (2007) The nonantibiotic anti-inflammatory effect of antimicrobial growth promoters, the real mode of action? A hypothesis. Poult Sci 86, 605-609.

26. Sukhotnik I, Yakirevich E, Coran AG, et al. (2002) Lipopolysaccharide endotoxemia reduces cell proliferation and decreases enterocyte apopotosis during intestinal adaptation in a rat model of short-bowel syndrome. Pediatr Surg Int 18, 615-619.

27. Scott MG, Rosenberger CM, Gold MR, et al. (2000) An $\alpha$-helical cationic antimicrobial peptide selectively modulates macrophage responses to lipopolysaccharide and girectly alters macrophage gene expression. J Immunol 165, $3358-3365$.

28. Hancock REW \& Scott MG (2000) The role of antimicrobial peptides in animal defenses. Proc Natl Acad Sci U S A 97, 8856-8861.

29. Reynoso ED, Elpek KG, Francisco L, et al. (2009) Intestinal tolerance is converted to autoimmune enteritis upon PD-1 ligand blockade. J Immunol 182, 2102-2112.

30. Cerón JM, Contreras-Moreno J, Puertollano E, et al. (2010) The antimicrobial peptide cecropin A induces caspase-independent cell death in human promyelocytic leukemia cells. Peptides 31, 1494-1503.

31. Dibner JJ \& Richards JD (2005) Antibiotic growth promoters in agriculture: history and mode of action. Poult Sci $\mathbf{8 4}$ $634-643$.

32. Ohh SH, Shinde PL, Jin Z, et al. (2009) Potato (Solanum tuberosum L. cv. Gogu valley) protein as an antimicrobial agent in the diets of broilers. Poult Sci 88, 1227-1234.

33. Panda AK, Rama Rao SV, Raju MVLN, et al. (2009) Effect of butyric acid on performance, gastrointestinal tract health and carcass characteristics in broiler chickens. Asian Aust J Anim Sci 22, 1026-1031.

34. Barszcz M \& Skomiał J (2011) The development of the small intestine of piglets-chosen aspects. J Anim Feed Sci 20, 3-15.

35. Drozdowski L \& Thomson ABR (2006) Intestinal mucosal adaptation. World J Gastroenterol 12, 4614-4627.

36. Shamoto K \& Yamauchi K (2000) Recovery responses of chick intestinal villus morphology to different refeeding procedures. Poult Sci 79, 718-723.

37. Kadhim KK, Zuki ABZ, Noordin MM, et al. (2010) Light and scanning electron microscopy of the intestine of the young red jungle fowl (Gallus callus). J Anim Vet Adv 9, $2729-2737$.

38. Buwjoom T, Yamauchi K, Erikawa T, et al. (2010) Histological intestinal alterations in chickens fed low protein diet. J Anim Physiol Anim Nutr 94, 354-361.

39. Chinese Animal Nutrition Association (1985) Tables of Feed Composition and Nutritive Value in China. Beijing: Agricultural Publishing House (in Chinese). 